\title{
Researching Parental Socialization Styles across Three Cultural Contexts: Scale ESPA29 Bi-Dimensional Validity in Spain, Portugal, and Brazil
}

\author{
Isabel Martínez ${ }^{1, *(\mathbb{C}}$, Fernando Garcia ${ }^{2}\left(\mathbb{C}\right.$, María C. Fuentes ${ }^{2}\left(\mathbb{D}\right.$, Feliciano Veiga ${ }^{3}(\mathbb{D}$, \\ Oscar F. Garcia ${ }^{4}$, , Yara Rodrigues ${ }^{3}$ (D) Edie Cruise $^{5}$ (D) and Emilia Serra ${ }^{4}$ (D) \\ 1 Department of Psychology, University of Castilla-La Mancha, Avda de los Alfares 44, 16071 Cuenca, Spain \\ 2 Department of Methodology of the Behavioral Sciences, University of Valencia, Av. Blasco Ibanez, 21, \\ 46010 Valencia, Spain; fernando.garcia@uv.es (F.G.); m.castillo.fuentes@uv.es (M.C.F.) \\ 3 Instituto de Educação, Universidade de Lisboa, Alameda da Universidade, 1649-013 Lisboa, Portugal; \\ fhveiga@ie.ulisboa.pt (F.V.); yaraiglesia@gmail.com (Y.R.) \\ 4 Department of Developmental and Educational Psychology, University of Valencia, Av. Blasco Ibanez, 21, \\ 46010 Valencia, Spain; oscar.f.garcia@uv.es (O.F.G.); emilia.serra@uv.es (E.S.) \\ 5 Department of Business Administration, University of Trier, Universitätsring 15, D-54296 Trier, Germany; \\ edie.cruise@gmail.com \\ * Correspondence: misabel.martinez@uclm.es; Tel.: +34-96-917-9100
}

Received: 2 December 2018; Accepted: 7 January 2019; Published: 11 January 2019

\begin{abstract}
Recent research that relates parenting with adolescent adjustment has shown the importance of considering the cultural context of the relationship. New results are emerging when considering the classical four-typologies model of parental socialization in some European and South-American countries. Among the instruments used in this emergent research is the Parental Socialization Scale ESPA29. This scale is a bi-dimensional parenting instrument that was specifically developed to measure the four parenting typologies, through the dimensions of acceptance/involvement and strictness/imposition. This study examines the good fit of the orthogonal bi-factor model based on the ESPA29 versus one-dimensional and bi-dimensional oblique alternative models, with three adolescent samples from 12 to 17 years old $(53.4 \%$ girls), from Spain $(N=826)$, Portugal $(N=752)$, and Brazil $(N=628)$. We applied structural equation models (SEMs) to analyze the fit of the models to the data. The results confirm a better fit to the data for the orthogonal bi-factor model versus one-dimensional and bi-dimensional oblique alternative models across country, adolescent sex, and the three age groups. Additionally, the convergent validity of the scale was proved by showing the relation of the two parenting dimensions with self-concept. The results guarantee the adequacy of the ESPA29 to measure parenting styles.
\end{abstract}

Keywords: parenting styles; parental warmth and strictness; adolescents; factorial invariance; multi-group analysis

\section{Introduction}

Research on parental socialization has coincided in pointing out two dimensions of parenting behavior. Although the labels utilized to denominate the dimensions have varied since the work of Maccoby and Martin (1983) [1] they have frequently been denominated as demandingness and responsiveness [2]. The demandingness dimension represents to what degree parents supervise and demand maturity of their children, assertively uphold their authority and use control over their children. The responsiveness dimension refers to the extent to which parents demonstrate emotional 
warmth, such as affection, and acceptance to their children, support them and utilize reasoning in their communication with them [3,4].

Earlier scholars utilized other labels such as control (Watson, 1928) [5] or attachment (Freud, 1933; Rogers, 1960) [6,7] to define the two main parenting dimensions. Symonds (1939) [8] used the terms acceptance/rejection and domination/submission, whereas Baldwin (1955) [9] named them emotional warmth/hostility and indifference/commitment. In the same line, Schaefer (1959) [10] named the two dimensions love/hostility and autonomy/control, while Sears, MacCoby, and Levin (1957) [11] used the labels of warmth and permissiveness/inflexibility, and Becker (1964) [3] talked about warmth/hostility and restriction/permissiveness. Baumrind [12-15] also confirmed two underlying dimensions in parent-child relationships named acceptance and paternal control. Later, in the work carried out by Steinberg and colleagues (1994) [16], two dimensions with similar connotations were identified: Acceptance/involvement and strictness/supervision [17,18]. Acceptance/involvement and strictness/imposition (ESPA29, Musitu \& García, 2001) [19], have also been utilized in different recent works [20-22]. To sum up, these two central parenting dimensions represent two different and theoretically unrelated parental behavior patterns [23] that when considered together lead to the four parental socialization styles: Authoritative-high use of demandingness parenting behaviors and high use responsiveness behaviors; neglectful—low use of both dimensions; indulgent-low use of demandingness and high use of responsiveness; and authoritarian style-high use of both dimensions $[1,18,24]$. Responsiveness has often been measured through parental warmth and acceptance, while demandingness has been operationalized as parental firmness [2].

The Parental Socialization Scale ESPA29 [19] is a bi-dimensional parenting instrument that was created with the precise purpose of measuring the aforementioned parenting typologies. The four parenting typologies are measured through the dimensions of acceptance/involvement and strictness/imposition, which are considered independent. The questionnaire specifically considers the distinction between socialization practices and styles $[23,25,26]$ using a contextual [23] and situational [26] approach. The ESPA29 analyzes behaviors showed by parents in specific situations that delineate day-to-day life within a family in Western culture. The instrument inquires about parental behavior within said situations through questions posed to the adolescent. The scale measures the use that mothers and fathers make of seven different practices of socialization: Warmth, indifference, reasoning, detachment, verbal scolding, physical punishment, and revoking privileges. The acceptance/involvement dimension consists of the practices of warmth and reasoning that compose the positive pole of the dimension, whereas indifference and detachment practices form the negative pole. The strictness/imposition dimension is formed with the verbal scolding, physical punishment, and revoking privileges practices. The practices that make up the two dimensions do not relate to each other; the strictness/imposition practices are impositive practices that are independent of the degree of acceptance/involvement. In this way, the possibility of a parent using an acceptance/involvement practice, such as reasoning, following the use of a strictness/imposition practice, such as scolding or revoking priveleges, is accounted for, as well as the possibility of a parent choosing to use only one of these practices of the two dimensions. The four parenting styles—authoritative, authoritarian, indulgent, and neglectful—are formed through the scores obtained on parental behavior comprising the acceptance/involvement and strictness/imposition dimensions.

The ESPA29 has been utilized to relate parenting with a wide variety of variables that capture adolescent adjustment using the four parenting styles [1,27-29] or the two main dimensions of parenting [30-32]. Among the adolescent adjustment criteria utilized are self-esteem [4], personal values [33], academic engagement [34], bullying and cyberbullying involvement [35], substance use [36], and antisocial behavior [37,38]. The instrument has been used mainly in Spain [31,33,37,39] but also in other countries like Portugal [40], Brazil [4,41], the United States [30], Italy [42], and Peru [43]. The ESPA29 scale is among the instruments used in emergent research that question authoritative parenting as the optimal style of socialization in any culture. Studies recently carried out in Europe and Latin America, namely in Spain [44], Italy [45], UK, Sweden, Slovenia, Czech Republic [46], 
Norway [22], Germany [47], Portugal [40], Turkey [48], Brazil [49], and Mexico [50], coincide in finding that, in those cultural contexts, the indulgent parenting style relates to equal or even higher adolescent adjustment than authoritative parenting.

The theoretical factor structure of the ESPA29 has been confirmed by the Exploratory Factor Analyses (EFAs) in Spain, where the scale was originally developed [19]. Subsequently, the factor structure has been confirmed in other languages and countries, including the Basque Country [51], Italy [42], and Brazil [41,52], using EFA and Procrustes Rotations [53]. The concurrent validity of the ESPA29 has also been successfully tested with two different samples from Spain [27,54]. Finally, Confirmatory Factor Analysis (CFA) was applied in the validation of the ESPA29 in a sample from the United States [30], although CFA has not yet been applied in Spain or any other country where the instrument has been used. Furthermore, the better fit of the two dimensions of the scale in an orthogonal model in comparison to oblique or one-dimensional models has not been confirmed.

The present study has two objectives. The first is to analyze the orthogonal bi-factor model based on ESPA29 as compared to one-dimensional and bi-dimensional oblique alternative models with three adolescent samples, one Spanish, one Portuguese, and another Brazilian. The second objective is to examine the invariance of the orthogonal bi-factor model based on the ESPA29 with the three samples of Spanish, Portuguese, and Brazilian adolescents. It is hypothesized that: (1) The bi-factor orthogonal model will provide a better fit to the data than the two alternative models; and (2) the adjustment of Spanish, Portuguese, and Brazilian samples will be invariant with respect to country, sex, and age.

Additionally, to test the convergent validity of the scale, the two dimensions-acceptance/ involvement and strictness/imposition-will be related to adolescent self-esteem, a classic criteria variable in parental socialization studies $[33,55,56]$. According to previous research [31,57], it is hypothesized that the practices of acceptance/involvement will relate positively to self-esteem, whereas the strictness/imposition dimension will relate negatively.

\section{Materials and Methods}

\subsection{Participants}

The sample was composed of 2,207 adolescents (53.4\% being women, 37.4\% Spanish, $34.1 \%$ Portuguese, and $28.5 \%$ Brazilian) covering the adolescent age range of 12 to 17 years old $(M=14.12$, $S D=1.67)($ see Table 1).

Table 1. Sample distribution of fathers' and mothers' parenting practices by country, sex, and age.

\begin{tabular}{|c|c|c|c|c|c|c|c|c|c|c|c|c|c|}
\hline \multirow{2}{*}{ Sample } & \multirow{2}{*}{$\mathbf{N}$} & \multicolumn{6}{|c|}{ Acceptance/Involvement } & \multicolumn{6}{|c|}{ Strictness/Imposition } \\
\hline & & Min & $\operatorname{Max}$ & $\mathbf{M}$ & SD & Skew & $\alpha 1$ & Min & Max & $\mathbf{M}$ & SD & Skew & $\alpha 1$ \\
\hline \multicolumn{14}{|l|}{ Father } \\
\hline All & 2207 & 1.00 & 4.00 & 3.11 & 0.53 & -0.73 & 0.96 & 1.00 & 3.38 & 1.72 & 0.41 & 0.65 & 0.93 \\
\hline Spanish & 826 & 1.28 & 4.00 & 3.17 & 0.45 & -0.66 & 0.94 & 1.00 & 3.04 & 1.70 & 0.37 & 0.62 & 0.92 \\
\hline Portuguese & 752 & 1.00 & 4.00 & 3.09 & 0.58 & -0.73 & 0.96 & 1.00 & 3.21 & 1.69 & 0.43 & 0.79 & 0.93 \\
\hline Brazilian & 629 & 1.08 & 4.00 & 3.07 & 0.54 & -0.62 & 0.96 & 1.00 & 3.38 & 1.79 & 0.41 & 0.51 & 0.93 \\
\hline Women & 1178 & 1.00 & 4.00 & 3.13 & 0.55 & -0.89 & 0.96 & 1.00 & 3.19 & 1.68 & 0.39 & 0.67 & 0.93 \\
\hline Men & 1029 & 1.00 & 4.00 & 3.09 & 0.50 & -0.50 & 0.95 & 1.00 & 3.38 & 1.78 & 0.42 & 0.63 & 0.93 \\
\hline $12-13$ & 770 & 1.10 & 4.00 & 3.21 & 0.50 & -0.73 & 0.95 & 1.00 & 3.38 & 1.84 & 0.43 & 0.47 & 0.93 \\
\hline $14-15$ & 776 & 1.00 & 4.00 & 3.01 & 0.54 & -0.78 & 0.96 & 1.00 & 3.17 & 1.71 & 0.39 & 0.68 & 0.92 \\
\hline $16-17$ & 661 & 1.00 & 3.97 & 3.02 & 0.52 & -0.68 & 0.95 & 1.00 & 2.88 & 1.61 & 0.35 & 0.29 & 0.92 \\
\hline \multicolumn{14}{|l|}{ Mother } \\
\hline All & 2207 & 1.38 & 4.00 & 3.20 & 0.47 & -0.51 & 0.95 & 1.00 & 3.38 & 1.75 & 0.40 & 0.60 & 0.93 \\
\hline Spanish & 826 & 1.38 & 4.00 & 3.18 & 0.46 & -0.53 & 0.96 & 1.00 & 3.06 & 1.71 & 0.39 & 0.62 & 0.93 \\
\hline Portuguese & 752 & 1.38 & 4.00 & 3.24 & 0.49 & -0.61 & 0.95 & 1.00 & 3.38 & 1.74 & 0.40 & 0.77 & 0.93 \\
\hline Brazilian & 629 & 1.68 & 4.00 & 3.18 & 0.47 & -0.37 & 0.95 & 1.02 & 3.15 & 1.82 & 0.38 & 0.39 & 0.91 \\
\hline Women & 1178 & 1.38 & 4.00 & 3.23 & 0.47 & -0.60 & 0.95 & 1.00 & 3.38 & 1.72 & 0.39 & 0.72 & 0.93 \\
\hline Men & 1029 & 1.38 & 4.00 & 3.16 & 0.47 & -0.41 & 0.94 & 1.00 & 3.17 & 1.80 & 0.41 & 0.47 & 0.93 \\
\hline $12-13$ & 770 & 1.68 & 4.00 & 3.30 & 0.46 & -0.47 & 0.94 & 1.00 & 3.38 & 1.88 & 0.42 & 0.47 & 0.93 \\
\hline $14-15$ & 776 & 1.38 & 4.00 & 3.18 & 0.48 & -0.57 & 0.95 & 1.00 & 3.04 & 1.73 & 0.39 & 0.63 & 0.92 \\
\hline $16-17$ & 661 & 1.38 & 4.00 & 3.11 & 0.47 & -0.44 & 0.94 & 1.00 & 3.02 & 1.64 & 0.37 & 0.68 & 0.92 \\
\hline
\end{tabular}




\subsection{Procedure}

Our sample was drawn from students attending educational centers from urban areas with a population of over one million in the three cities where the study was carried out, situated on the East Coast of Spain, the Middle West Coast of Portugal, and in the Southeast of Brazil. The data were collected from 16 secondary schools (5 Spanish, 5 Portuguese, and 6 Brazilian) chosen at random utilizing the simple random sampling method from a comprehensive list of those cities' schools.

We obtained approval to conduct this research through the Valencian Research Ethics Committee of the Program for the Promotion of Scientific Research, Technological Development and Innovation in Spain. After that, it was necessary for each of the Research and Evaluation Boards in the cities where the study was carried out to approve this research. After having obtained their approval, we were then allowed to conduct the study in the individual secondary schools by the head or principal of each educational center. The next step of approval was then granted by each teacher or instructor for our questionnaires to be completed during their class time. Our team informed each student and their parents or legal guardians of the nature of our study through a letter, which was then signed by both a parent/guardian and the student, ensuring we were granted permission from a parent/guardian, as well as assent from the student agreeing to partake in the research voluntarily. The anonymous questionnaires were only administered to those students who agreed to complete it and had parental/guardian permission to do so. We examined the questionnaires for aberrant response patterns, such as reporting implausible inconsistencies between negatively and positively worded responses or "maximum-scale" behavior [44,57-59]. About $4 \%(n=83)$ of the cases contained such inconsistencies and were therefore eliminated from the sample.

\subsection{Instruments}

\subsubsection{Parental Socialization}

The Parental Socialization Scale ESPA29 [19] is a self-report instrument, designed to examine parenting styles via children's and adolescents' responses, aged 10 to 18 years. This instrument measures distinct parenting practices in the context of day-to-day family life. These specific parenting practices are measured as responses to 29 situational contexts which are common occurrences between adolescents and their parents. Within the 29 situations, there are 13 which give the context of obedience in which the family norm is followed (e.g., "If I bring home my report card with good grades") and 16 which portray a context of disobedience in which the family norm is contravened (e.g., "If they find out that I have lied"). The parenting practices of warmth ("He/she shows affection") and indifference ("He/she seems indifferent) are measured in response to the 13 contexts of obedience while the parenting practices of reasoning ("He/she talks to me"), detachment ( $\mathrm{It}^{\prime} \mathrm{s}$ the same to him/her"), verbal scolding ("He/she scolds me"), physical punishment ("He/she hits me"), and revoking privileges ("He/she takes something away from $\mathrm{me}^{\text {") }}$ ) are measured in response to the 16 contexts of disobedience. The adolescent respondent uses a 4-point scale to indicate the frequency in which their mother and father make use of the seven specified parenting practices, with 1 meaning "never", 2 "sometimes", 3 "most times", and 4 "always".

To calculate the score of the acceptance/involvement dimension, the scores of the detachment and indifference subscales are first inverted given their negative relation to the dimension. Then, the scores of warmth, reasoning, indifference, and detachment subscales can be averaged to produce the aggregate score for the dimension. Similarly, the strictness/imposition dimension score is also comprised of an average of the revoking privileges, verbal scolding, and physical punishment subscales. No inversion is necessary in this case as all three subscales relate positively to the dimension. The aggregate dimension scores for each sample across country, sex, and age group can be found in Table 1.

The instrument needed to be translated from Spanish into Portuguese in order to carry out this study. We first obtained permission from the scale's authors to do so and then selected three bilingual (Spanish- and Portuguese-speaking) colleagues to perform the Spanish to Portuguese translation. 
The bilingual team verified equivalence in grammar, clarity, and content item by item. Once that was completed, a back-translation was performed by an additional bilingual researcher independent from the present study. Finally, the scale's authors reviewed the back-translated Portuguese to Spanish version for final verification and approval $[41,60]$.

\subsubsection{Multidimensional Self-Concept}

The AF5 [61,62] measures self-concept through five dimensions: Academic (e.g., "I work very hard in class"), social (e.g., "I make friends easily"), emotional (e.g., reversed item, "It is difficult for me to talk to strangers"), family (e.g., "I am happy at home"), and physical (e.g., "I take good care of my physical health"). There is a total of 30 items that comprise the scale divided into six per dimension. The participant rates the items, which are statements, according to his/her level of agreement or disagreement using a 99-point scale (portrayed by a thermometer), which ranges from 1, representing complete disagreement, to 99 , representing complete agreement.

The factor structure of the AF5 was confirmed with exploratory and confirmatory analyses [57-65] and no method effect appears to be associated with negatively-worded items $[58,59]$. The instrument was originally developed and validated in Spain [61] and has also been validated in English [60], Basque [64], and Catalan languages [65]. Numerous studies have utilized the AF5 to relate self-esteem to other variables (e.g., gender stereotypes, body image, and sport practice [66], physical activity [67], motivational climate [68], food neophobia [57], substance use [69-71], participation in school violence [37], and subjective well-being [72]) with consistent results. Lastly, higher adolescent self-esteem has been found to be related to the ESPA29 dimension of parental acceptance/involvement, whereas lower adolescent self-esteem has been related to the strictness/imposition dimension in different studies [30,31,57].

\subsection{Data Analysis}

We began by examining how well the theoretical orthogonal two-factor model of socialization fit the data against two alternative models. We first tested a one-factor model, which conceives parenting as a one-dimensional construct (e.g., one-dimensional parental acceptance-rejection socialization theory [73]). Next, we tested the oblique (correlated) two-factor model, whereby parenting is as a bi-dimensional construct in which parental acceptance/involvement and parental strictness/imposition are correlated $[25,46,74]$. Third, we tested the theoretical orthogonal two-dimensional model. Under this model, parenting is conceived as a bi-dimensional construct where the underpinning parenting dimensions are unrelated or orthogonal. In this model, we free the covariate between the two factors of the bi-factor model. This theoretical orthogonal bi-factor model is the same model as the previous oblique one but with the two dimensions non-correlated $[23,26,27,30]$. We freed error covariances for the strongly correlated pairs of parenting practices whose content was more alike $[30,57,75,76]$.

In order to analyze the fit of the models to the data, we calculated structural equation models (SEMs) using EQS 6.1 (Multivariate Software, Encino, CA, USA) [9]. We employed the maximum likelihood robust estimation method due to the deviation of the multinormal data (all Mardia's normalized coefficient $>25, p<0.01$ ). In order to control non-normality, the scale of parenting practices was transformed into quartiles [59,77], the correlation matrices used were polychoric, and the models were tested with the Satorra-Bentler chi-squared statistic [78] and associated robust confirmatory fit index provided by EQS 6.1 [9]. The criteria used are in line with those proposed by Hu and Bentler [79] and are the usual criteria utilized in this type of analysis [30,57].

The CFA technique allows for the adjustment of the model to the data to be evaluated through the chi-squared value obtained. However, the chi-squared test has shown serious problems of sensitivity to sample size $[21,80,81]$. Methodological studies provide other fit indexes which have the advantage of a pre-established cut-off criteria $[30,60,63,81]$. We applied the following indexes: Root mean squared error of approximation (RMSEA), where values lower than 0.08 are considered acceptable; normed fit 
index, incremental fit index, and comparative fit index, NFI, IFI, and CFI, whose value must exceed 0.90; and the information criterion of Akaike, AIC (Akaike information criterion), where the lowest value indicates the highest parsimony [82]. RMSEA too often falsely indicates a poorly fitting model for small $d f$ models [83], i.e., one-dimensional and two-dimensional parenting practices models.

To test the second hypothesis-the invariance of the country, sex, and age sample-we evaluated four nested models that progressively increased the number of restrictions by constraining free parameters. After establishing what the model baseline was, we conducted the following sequence of increasingly more restrictive tests of invariance across the three samples: Model A, unconstrained, without any restrictions across any parameters for the thee samples examined; Model B, we fixed factor pattern coefficients; Model C, we fixed factor variances and covariances; and Model D, finally, we established the equality of the error variances. At each step, when the parameters of the previous model are restricted, the degrees of freedom of the new model increase and chi-square also tends to increase. When $\Delta \times 2$ value is statistically significant, the null hypothesis that the models are equivalent to, it rejects. Cheung and Rensvold (2002) [81] provided a solution to the oversensitivity problem of $\Delta \times 2$ to sample size by examining the invariance of nested models via the $\Delta C F I$. After analyzing 20 different adjustment indexes, these authors (2002, p. 251) [81] concluded that an absolute $\Delta C F I$ value higher than 0.01 (i.e., $|\Delta \mathrm{CFI}|>0.01$ ) signifies a meaningful fall in fit.

\section{Results}

\subsection{Fitting of Model to Data from the One-Dimensional to Two-Dimensional Orthogonal Model}

First, we constrained the data to test their adjustment with the one-dimensional model (Table 2). The statistics produced from that calculation did not reach cut-off values, resulting in a poor fit of the model to the data (father, RMSEA $=0.20, \mathrm{CFI}=0.80, \mathrm{IFI}=0.80, \mathrm{NFI}=0.80, \mathrm{AIC}=710$; mother, $\mathrm{RMSEA}=0.18, \mathrm{CFI}=0.82, \mathrm{IFI}=0.82, \mathrm{NFI}=0.81, \mathrm{AIC}=566$ ). Second, we constrained the data to test their adjustment with the two-dimensional oblique model, which resulted in a significantly improved fit against the previous model (father, RMSEA $=0.10, \mathrm{CFI}=0.96$, IFI $=0.96, \mathrm{NFI}=0.96$, AIC $=144$; mother, $\mathrm{RMSEA}=0.11, \mathrm{CFI}=0.96, \mathrm{IFI}=0.96, \mathrm{NFI}=0.96, \mathrm{AIC}=163$ ). Finally, we constrained the data to test their adjustment with the theoretical orthogonal model, which did not yield a fall in fit compared to the oblique model (father, RMSEA $=0.10, \mathrm{CFI}=0.95, \mathrm{IFI}=0.95, \mathrm{NFI}=0.95, \mathrm{AIC}=160$; mother, $\mathrm{RMSEA}=0.08, \mathrm{CFI}=0.97, \mathrm{IFI}=0.96, \mathrm{NFI}=0.96, \mathrm{AIC}=100)$, although the orthogonality restriction has been included by fixing the covariation between the two factors to 0 (i.e., Acceptance/involvement and strictness/imposition).

Table 2. Confirmatory factor analysis of fathers' and mothers' parenting practices.

\begin{tabular}{cccccccc}
\hline Model & $\mathbf{S - B} \boldsymbol{X}^{2}$ & $d f$ & CFI & IFI & NFI & AIC & RMSEA [90\%CI] \\
\hline $\begin{array}{c}\text { Father } \\
\text { One-dimensional }\end{array}$ & $726.36^{* *}$ & 8 & 0.803 & 0.803 & 0.802 & 710.36 & $0.202[0.189-0.214]$ \\
Oblique & $157.73^{* *}$ & 7 & 0.959 & 0.959 & 0.957 & 143.73 & $0.099[0.086-0.112]$ \\
Orthogonal & $176.18^{* *}$ & 8 & 0.954 & 0.954 & 0.952 & 160.18 & $0.098[0.085-0.110]$ \\
\hline Mother & & & & & & & \\
One-dimensional & $581.83^{* *}$ & 8 & 0.815 & 0.816 & 0.813 & 565.83 & $0.180[0.168-0.193]$ \\
$\quad$ Oblique & $176.56^{* *}$ & 7 & 0.957 & 0.955 & 0.955 & 162.56 & $0.105[0.092-0.118]$ \\
Orthogonal & $115.96^{* *}$ & 8 & 0.965 & 0.963 & 0.963 & 99.96 & $0.078[0.066-0.091]$ \\
\hline
\end{tabular}

$\mathrm{S}-\mathrm{B} \chi^{2}$, Satorra-Bentler chi-squared; $d f$, degrees of freedom; CFI, comparative fit index; IFI, incremental fit index; NFI, normed fit index; AIC, Akaike information criterion (computed as $\chi^{2}-2 d f$ ); RMSEA, root mean squared error of approximation. All indexes are the robust version. In oblique and orthogonal bi-dimensional models, covariation between the residuals errors more correlated were added. ${ }^{* *} p<0.01$. 


\subsection{Multi-Group Confirmatory Factor Analyses of Invariance}

Multi-group confirmatory factor analyses of invariance across country, age, and sex groups are reported in Table 3. The unconstrained parsimoniously orthogonal model indicated a good fit, suggesting a common factor structure across country, sex, and age groups. Constraining the measurement weights, structural variances, and covariances, and measurement residuals yielded non-significant changes in fit across country, sex, and age groups, $|\Delta \mathrm{CFI}|<0.01$.

Table 3. Multi-sample analysis of invariance across country, age, and sex of fathers' and mothers' parenting practices.

\begin{tabular}{|c|c|c|c|c|c|c|c|c|}
\hline Model & S-B $\chi^{2}$ & $d f$ & CFI & $\Delta \mathrm{CFI}$ & IFI & NFI & AIC & RMSEA $(90 \%$ CI) \\
\hline \multicolumn{9}{|l|}{$\begin{array}{r}\text { COUNTRY } \\
\text { Father }\end{array}$} \\
\hline Model A & $183.70^{* *}$ & 24 & 0.953 & & 0.953 & 0.953 & 135.70 & $0.055(0.048-0.062)$ \\
\hline Model B & $247.13^{* *}$ & 34 & 0.945 & 0.008 & 0.945 & 0.937 & 179.13 & $0.053(0.047-0.060)$ \\
\hline Model C & $274.20^{* *}$ & 32 & 0.939 & 0.006 & 0.939 & 0.930 & 21.20 & $0.053(0.047-0.059)$ \\
\hline Model D & $372.89 * *$ & 52 & 0.932 & 0.007 & 0.932 & 0.922 & 268.89 & $0.053(0.048-0.058)$ \\
\hline \multicolumn{9}{|l|}{ Mother } \\
\hline Model A & $146.47^{* *}$ & 24 & 0.962 & & 0.963 & 0.956 & 98.47 & $0.048(0.041-0.056)$ \\
\hline Model B & $163.42^{* *}$ & 34 & 0.960 & 0.002 & 0.960 & 0.950 & 95.42 & $0.042(0.035-0.048)$ \\
\hline Model C & 185.17 ** & 38 & 0.954 & 0.006 & 0.955 & 0.944 & 109.17 & $0.042(0.036-0.048)$ \\
\hline Model D & $245.66^{* *}$ & 52 & 0.951 & 0.003 & 0.951 & 0.939 & 141.66 & $0.041(0.036-0.046)$ \\
\hline \multicolumn{9}{|l|}{ SEX } \\
\hline \multicolumn{9}{|l|}{ Father } \\
\hline Model A & $181.80 * *$ & 16 & 0.955 & & 0.955 & 0.951 & 149.80 & $0.069(0.060-0.078)$ \\
\hline Model B & $191.84^{* *}$ & 21 & 0.953 & 0.002 & 0.954 & 0.948 & 149.84 & $0.061(0.053-0.069)$ \\
\hline Model C & $204.37^{* *}$ & 23 & 0.951 & 0.002 & 0.945 & 0.945 & 158.37 & $0.060(0.052-0.067)$ \\
\hline Model D & $239.05^{* *}$ & 30 & 0.951 & 0.000 & 0.951 & 0.945 & 1790.05 & $0.056(0.050-0.063)$ \\
\hline \multicolumn{9}{|l|}{ Mother } \\
\hline Model A & $127.53 * *$ & 16 & 0.964 & & 0.965 & 0.960 & 95.53 & $0.056(0.047-0.065)$ \\
\hline Model B & $137.85^{* *}$ & 19 & 0.963 & 0.001 & 0.963 & 0.957 & 99.85 & $0.050(0.042-0.058)$ \\
\hline Model C & $144.22 * *$ & 21 & 0.961 & 0.002 & 0.961 & 0.954 & 102.22 & $0.049(0.041-0.057)$ \\
\hline Model D & $168.96^{* *}$ & 30 & 0.962 & -0.001 & 0.962 & 0.954 & 108.96 & $0.046(0.039-0.053)$ \\
\hline \multicolumn{9}{|l|}{ AGE } \\
\hline \multicolumn{9}{|l|}{ Father } \\
\hline Model A & $193.71^{* *}$ & 24 & 0.954 & & 0.954 & 0.948 & 145.71 & $0.057(0.049-0.064)$ \\
\hline Model B & $218.83 * *$ & 34 & 0.950 & 0.004 & 0.950 & 0.941 & 15.83 & $0.050(0.043-0.056)$ \\
\hline Model C & 234.24 ** & 38 & 0.946 & 0.004 & 0.947 & 0.937 & 158.24 & $0.048(0.042-0.054)$ \\
\hline Model D & $279.11 * *$ & 52 & 0.949 & -0.003 & 0.949 & 0.939 & 175.11 & $0.045(0.039-0.050)$ \\
\hline \multicolumn{9}{|l|}{ Mother } \\
\hline Model A & $16.70^{* *}$ & 24 & 0.957 & & 0.958 & 0.951 & 112.70 & $0.051(0.043-0.058)$ \\
\hline Model B & $186.32 * *$ & 34 & 0.952 & 0.005 & 0.953 & 0.943 & 118.32 & $0.045(0.039-0.051)$ \\
\hline Model C & $199.45^{* *}$ & 38 & 0.949 & 0.003 & 0.950 & 0.939 & 123.45 & $0.044(0.038-0.050)$ \\
\hline Model D & $249.84 * *$ & 52 & 0.949 & 0.000 & 0.950 & 0.937 & 145.84 & $0.042(0.036-0.047)$ \\
\hline
\end{tabular}

S-B $\chi^{2}$, Satorra-Bentler chi-squared; $d f$, degrees of freedom; CFI, comparative fit index; IFI, incremental fit index; NFI, normed fit index; AIC, Akaike information criterion (computed as $\chi^{2}-2 d f$ ); RMSEA, root mean squared error of approximation. All indexes are the robust version. ${ }^{* *} p<0.01$. Model A, unconstrained baseline model; model B, measurement weights; model $\mathrm{C}$, structural variances and covariances; and model D, measurement residuals.

Table 4 gives an overview of the factor loadings estimated in the most constrained model. Invariance testing across language, sex, and adolescent age indicated analogous functioning of the orthogonal bi-factor model in all of the samples examined.

Additionally, we calculated the two parenting dimensions, acceptance/involvement and strictness/imposition, with raw data. Father parenting practices were modestly correlated, $r=0.16$, 
$R^{2}=0.02(2 \%), p<0.01$. Neither the $95 \%$ CI $(0.12,0.20)$ nor the $95 \%$ CI proportion of variance $(0.01$, $0.04)$ included zero. In the same line, mother parenting dimensions were also modestly correlated, $r=0.09, R^{2}=0.01(1 \%), p<0.01$. Although the $95 \% \mathrm{CI}(0.09,0.05)$ did not included zero, the $95 \% \mathrm{CI}$ proportion of variance $(0.00,0.02)$ did include zero.

Table 4. Confirmatory factor analysis (CFA) standardized factor loadings of fathers' and mothers' parenting practices of the most constrained model.

\begin{tabular}{|c|c|c|c|c|c|c|}
\hline \multirow{2}{*}{ Parental Practice } & \multicolumn{3}{|c|}{ Father } & \multicolumn{3}{|c|}{ Mother } \\
\hline & Sex & Country & Age & Sex & Country & Age \\
\hline \multicolumn{7}{|l|}{ Acceptance/involvement } \\
\hline Warmth & $0.46^{* *}$ & $0.50 * *$ & $0.45^{* *}$ & $0.52 * *$ & $0.51 * *$ & $0.52 * *$ \\
\hline Indifference & $-0.70^{\mathrm{a}}$ & $-0.71^{a}$ & $-0.70^{\mathrm{a}}$ & $-0.68^{a}$ & $-0.69^{a}$ & $-0.68^{a}$ \\
\hline Detachment & $-0.53^{* *}$ & $-0.52 * *$ & $-0.53^{* *}$ & $-0.51^{* *}$ & $-0.52 * *$ & $-0.51 * *$ \\
\hline Reasoning & $0.81^{* *}$ & $0.80 * *$ & $0.81^{* *}$ & $0.74^{* *}$ & $0.74 * *$ & $0.74^{* *}$ \\
\hline \multicolumn{7}{|l|}{ Strictness/imposition } \\
\hline Verbal scolding & $0.56^{\mathrm{a}}$ & $0.56^{\mathrm{a}}$ & $0.56^{\mathrm{a}}$ & $0.58^{\mathrm{a}}$ & $0.58^{\mathrm{a}}$ & $0.56^{\mathrm{a}}$ \\
\hline Physical punishment & $0.49 * *$ & $0.46^{* *}$ & $0.49^{* *}$ & $0.47^{* *}$ & $0.48^{* *}$ & $0.53 * *$ \\
\hline Revoking privileges & $0.84 * *$ & $0.84^{* *}$ & $0.85^{* *}$ & $0.76^{* *}$ & $0.76^{* *}$ & $0.79 * *$ \\
\hline
\end{tabular}

\subsection{Reliability}

Father alpha reliability coefficients for the total scale were 0.93 , in the Spanish sample, 0.92 , in the Portuguese, 0.93, in the Brazilian, 0.93, in women, 0.93, in men, 0.93, in the 12-13-year-old age group, 0.93 , in the 14-15-year-old age group, 0.92 , and in the 16-17-year-old age group, 0.92 . Mother alpha reliability coefficients for the total scale were 0.93 , in the Spanish sample, 0.93, in the Portuguese, 0.93, in the Brazilian, 0.91, in women, 0.93, in men, 0.93, in the 12-13-year-old age group, 0.93, in the 14-15-year-old age group, 0.92, and in the 16-17-year-old age group, 0.92 (see Table 1).

\subsection{Relation with Self-Concept Dimensions}

Regarding the relation between the ESPA29 acceptance/involvement dimension and self-concept, the Pearson correlation revealed that father and mother scales were positively associated with academic, social, family, and physical self-concept. With respect to the strictness/imposition dimension, the father scales showed a negative association with academic, social, emotional, and family self-concept, as well as the mother scales with emotional and family self-concept (Table 5).

Table 5. Correlations and $R^{2}$ between two main parental socialization dimensions with five self-concept dimensions.

\begin{tabular}{|c|c|c|c|c|}
\hline \multirow{2}{*}{$\begin{array}{l}\text { Self-concept } \\
\text { Dimensions }\end{array}$} & \multicolumn{2}{|c|}{ Acceptance/Involvement } & \multicolumn{2}{|c|}{ Strictness/Imposition } \\
\hline & $r(95 \% \mathrm{CI})$ & $R^{2}(95 \% \mathrm{CI})$ & $r(95 \% \mathrm{CI})$ & $R^{2}(95 \% \mathrm{CI})$ \\
\hline \multicolumn{5}{|l|}{ Father } \\
\hline Academic & $0.234(0.194,0.273)$ & $0.05(0.04,0.07) *$ & $-0.143(-0.184,-0.102)$ & $0.02(0.03,0.01) *$ \\
\hline Social & $0.168(0.127,0.208)$ & $0.03(0.02,0.04) *$ & $-0.128(-0.169,-0.087)$ & $0.02(0.03,0.01) *$ \\
\hline Emotional & $-0.011(-0.053,0.031)$ & $0.00(0.00,0.00)^{+}$ & $-0.034(-0.076,0.008)$ & $0.00(0.01,0.00)^{+}$ \\
\hline Family & $0.421(0.386,0.455)$ & $0.18(0.15,0.21)^{* *}$ & $-0.325(-0.362,-0.287)$ & $0.11(0.13,0.08)^{* *}$ \\
\hline Physical & $0.133(0.092,0.174)$ & $0.02(0.01,0.03) *$ & $-0.092(-0.133,-0.050)$ & $0.01(0.02,0.00)^{+}$ \\
\hline \multicolumn{5}{|l|}{ Mother } \\
\hline Academic & $0.245(0.205,0.284)$ & $0.06(0.04,0.08) *$ & $0.018(-0.024,0.060)$ & $0.00(0.00,0.00)^{+}$ \\
\hline Social & $0.191(0.150,0.231)$ & $0.04(0.02,0.05) *$ & $0.011(-0.031,0.053)$ & $0.00(0.00,0.00)^{+}$ \\
\hline Emotional & $-0.030(-0.072,0.012)$ & $0.00(0.01,0.00)^{+}$ & $-0.178(-0.218,-0.137)$ & $0.03(0.05,0.02) *$ \\
\hline Family & $0.409(0.374,0.443)$ & $0.17(0.14,0.20) * *$ & $-0.160(-0.200,-0.119)$ & $0.03(0.04,0.01) *$ \\
\hline Physical & $0.135(0.094,0.176)$ & $0.02(0.01,0.03) *$ & $0.051(0.009,0.093)$ & $0.00(0.00,0.01)^{+}$ \\
\hline
\end{tabular}


The size of the correlations between parental socialization dimensions and self-concept is similar to those reported in previous studies that examine the relation between these two variables $[19,30,55,56]$. It was noted that family self-concept correlation with acceptance/involvement was $0.42\left(r^{2}=18 \%\right)$ for the father and $0.41\left(R^{2}=17 \%\right)$ for the mother. Additionally, strictness/imposition correlation with family self-concept was $-0.33\left(R^{2}=11 \%\right)$ for the father and $-0.16\left(R^{2}=3 \%\right)$ for the mother $[19,84]$. In addition, it was noted that strictness/imposition correlation with emotional self-concept was -0.18 $\left(R^{2}=3 \%\right)$ for the mother.

\section{Discussion}

The results of this work confirm the orthogonal bi-dimensional structure of the Parental Socialization Scale ESPA29 [19] with three samples of adolescents from Spain, Portugal, and Brazil. Confirmatory Factor Analyses confirm a better fit to the data of the orthogonal bi-factor model as compared to competitive one-dimensional and bi-dimensional oblique alternative models of parenting across country (Spain, Portugal, and Brazil), adolescent sex, and three age groups from 12-17 years old. These results are consistent for both fathers' and mothers' scores, supporting the two dimensions of parental conduct proposed in the ESPA29, where the dimension of acceptance/involvement is measured with the warmth and reasoning subscales, which loaded positively onto the dimension, and indifference and detachment subscales, which loaded negatively. Meanwhile, the subscales of physical punishment, verbal scolding, and revoking privileges loaded positively onto the strictness/imposition dimension. Furthermore, combined multi-sample nested factor analysis showed that the ESPA29 orthogonal bi-dimensional model is largely invariant across related samples of country (Spain, Portugal, and Brazil), sex, and adolescent age for both fathers' and mothers' scores.

The results of the study underline the importance of considering parental practices of socialization in two independent, non-related dimensions $[1,23,26]$ in oposition to one-dimensional or two dimensional oblique models. One-dimensional models [73] would only include a part of the total variance, without considering all the variation of the parenting socialization construct. Moreover, oblique models, where the two parenting dimensions are related, do not allow for the proper measurement of the four parenting styles, since the dimensions will not equally represent the different parenting styles that are defined. For example, the strictness dimension is shared by authoritative and authoritarian styles and should equally define both styles, however, "monitoring", which has been widely used to capture strictness $[16,18]$, has received serious critiques for not equally representing the two styles (authoritative and authoritarian [25,74]). Although monitoring was initially conceptualized as a parenting practice involving active parents' attempts to watch over children as a resource of firm control or strictness $[16,18]$, researchers have complained that most of the adolescent outcomes that parental monitoring predicts are explained by adolescents' spontaneous disclosure of information to parents (characteristic of authoritative parenting), but not by parents' attempts to obtain accurate information (characteristic of authoritarian parenting) [25,27,46,74,85-88].

Therefore, the ESPA29 conforms to the theoretical model of parenting repeatedly identified in the literature during the last ten decades $[1,5,8,11]$, which identifies two main parental dimensions $[16,18,20,21]$. When these two dimensions are considered together, they make up the classical parenting typology, which establishes four family styles of parenting: Authoritative, authoritarian, indulgent, and neglectful. In this way, the quadripartite model contemplates the differentiation between neglectful and indulgent parenting unlike tripartite models, such as Baumrind's model [12-15], which ignores variations in warmth among families characterized by low levels of control. In doing so, tripartite models use a single category labeled 'permissive' to describe these two parenting groups (Lamborn et al. 1991, p. 1050)".

Additionally, the convergent validity of the scale in those samples was proved by showing the relation of the two parenting dimensions with self-concept, a classic criteria variable in parenting studies $[1,16,18,20,21]$. The results show that the acceptance/involvement dimension is positively related with self-esteem for mothers' and fathers' scores, whereas the strictness/imposition dimension 
is negatively-related with adolescents' self-esteem for mothers' and fathers' scores. Our results are like those reported in other studies which examine the parenting and self-esteem relationship [89] in that positive parenting is associated with high self-esteem, whereas negative parenting is associated with low self-esteem $[16,18,46]$. Futhermore, similar results are reported in other studies using the ESPA29 [27,30,31].

This article is not without limitations. Fathers' and mothers' scores were calculated from the adolescents' responses, though research indicates that adolescent self-reports contribute to our comprehension of the family process in a meaningful way [16], and similar results have been obtained on parenting styles despite different methods of data collection $[16,18,28,29]$. Second, our results are in the context of three countries (Spain, Portugal, and Brazil), but possible differences must be kept in mind if extrapolating to other countries and cultures. Despite the aforementioned limitations, the present work fully corroborates the bi-dimensional structure of parenting as conceptualized and measured by the ESPA29.

\section{Conclusions}

The present work reinforces the bi-dimensional structure of parenting. The theoretical structure of the Parental Socialization Scale ESPA29 [19], is confirmed with CFA in three samples from Spain, Portugal, and Brazil. The bi-dimensional orthogonal model results in a better fit as compared to the competitive one-dimensional and bi-dimensional oblique alternative models. The results are consistent across country, adolescent sex, and the three age groups from 12 to 17 years old. Therefore, the results confirm the adequacy of the ESPA29 scale to measure parenting styles.

Author Contributions: All authors conceived the study, analyzed the data, and helped to draft and revise the manuscript. In addition, all authors have read and approved the final manuscript.

Funding: The research reported in this article has been partially supported by Grants UID/CED/04107/2016 (FCT-Fundação para a Ciência e Tecnologia, IP., no âmbito da Unidade de Investigação e Desenvolvimento em Educação e Formação), ACIF/2016/431, and BEFPI/2017/058 (Valencian Regional Government, and European Social Fund), and FPU16/00988 (Ministry of Science, Innovation and Universities, Government of Spain).

Conflicts of Interest: The authors declare no conflict of interest. The funders had no role in the design of the study; in the collection, analyses, or interpretation of data; in the writing of the manuscript, or in the decision to publish the results.

\section{References}

1. Maccoby, E.E.; Martin, J.A. Socialization in the context of the family: Parent-child interaction. In Handbook of Child Psychology; Mussen, P.H., Ed.; Wiley: New York, NY, USA, 1983; Volume 4, pp. 1-101.

2. Steinberg, L. Psychological control: Style or substance? In New Directions for Child and Adolescent Development: Changes in Parental Authority during Adolescence; Smetana, J.G., Ed.; Jossey-Bass: San Francisco, CA, USA, 2005; pp. 71-78. [CrossRef]

3. Becker, W.C.; Krug, R.S. A Circumplex Model for Social-Behavior in Children. Child Dev. 1964, 35, 371-396. [CrossRef]

4. Martínez, I.; García, J.F. Internalization of Values and Self-Esteem among Brazilian Teenagers from Authoritative, Indulgent, Authoritarian, and Neglectful Homes. Adolescence 2008, 43, 13-29.

5. Watson, J.B. Psychological Care of Infant and Child; G. Allen \& Unwin: London, UK, 1928; Available online: http:/ / psycnet.apa.org/record/1928-02003-000 (accessed on 10 January 2019).

6. Freud, S. New Introductory Lectures on Psycho-Analysis; Hogarth Press: London, UK, 1933.

7. Rogers, C.R. A Therapist's View of Personal Goals. (Pendle Hill Pamphlet 108); Pendle Hill: Oxford, UK, 1960.

8. Symonds, P.M. The Psychology of Parent-Child Relationships; Appleton-Century-Crofts: New York, NY, USA, 1939.

9. Bentler, P.M. EQS Structural Equations Program Manual; Multivariate Software: Encino, CA, USA, $1995 ;$ p. 619.

10. Schaefer, E.S. A Circumplex Model for Maternal Behavior. J. Abnorm. Soc. Psychol. 1959, 59, $226-235$. [CrossRef]

11. Sears, R.R.; Maccoby, E.E.; Levin, H. Patterns of Child Rearing; Row, Peterson: Evanston, IL, USA, $1957 ;$ p. 549. 
12. Baumrind, D. Child Cares Practices Anteceding Three Patterns of Preschool Behavior. Genet. Psychol. Monogr. 1967, 75, 43-88.

13. Baumrind, D. Authoritarian Vs Authoritative Parental Control. Adolescence 1968, 3, 255-272.

14. Baumrind, D. Current patterns of Parental Authority. Dev. Psychol. 1971, 4, 1-103. [CrossRef]

15. Baumrind, D. Rearing competent children. In Child Development Today and Tomorrow; Damon, W., Ed.; Jossey-Bass: San Francisco, CA, USA, 1989; pp. 349-378.

16. Steinberg, L.; Lamborn, S.D.; Darling, N.; Mounts, N.S.; Dornbusch, S.M. Over-Time Changes in Adjustment and Competence among Adolescents from Authoritative, Authoritarian, Indulgent, and Neglectful Families. Child Dev. 1994, 65, 754-770. [CrossRef]

17. Chao, R.K. Beyond Parental Control and Authoritarian Parenting Style: Understanding Chinese Parenting through the Cultural Notion of Training. Child Dev. 1994, 65, 1111-1119. [CrossRef]

18. Lamborn, S.D.; Mounts, N.S.; Steinberg, L.; Dornbusch, S.M. Patterns of Competence and Adjustment among Adolescents from Authoritative, Authoritarian, Indulgent, and Neglectful Families. Child Dev. 1991, 62, 1049-1065. [CrossRef]

19. Musitu, G.; García, F. ESPA29: Parental Socialization Scale in Adolescence; Tea: Madrid, Spain, 2001; p. 64.

20. Martínez, I.; Murgui, S.; Garcia, O.F.; Garcia, F. Parenting in the Digital Era: Protective and Risk Parenting Styles for Traditional Bullying and Cyberbullying Victimization. Comput. Hum. Behav. 2019, 90, 84-92. [CrossRef]

21. Garcia, O.F.; Serra, E.; Zacares, J.J.; Garcia, F. Parenting Styles and Short- and Long-Term Socialization Outcomes: A Study among Spanish Adolescents and Older Adults. Psychosoc. Interv. 2018, 27, 153-161. [CrossRef]

22. Lund, I.; Scheffels, J. 15-Year-Old Tobacco and Alcohol Abstainers in a Drier Generation: Characteristics and Lifestyle Factors in a Norwegian Cross-Sectional Sample. Scand. J. Public Health 2018. [CrossRef]

23. Darling, N.; Steinberg, L. Parenting Style as Context: An Integrative Model. Psychol. Bull. 1993, 113, 487-496. [CrossRef]

24. Chao, R.K. Extending Research on the Consequences of Parenting Style for Chinese Americans and European Americans. Child Dev. 2001, 72, 1832-1843. [CrossRef]

25. Kerr, M.; Stattin, H. What Parents Know, how they Know it, and several Forms of Adolescent Adjustment: Further Support for a Reinterpretation of Monitoring. Dev. Psychol. 2000, 36, 366-380. [CrossRef]

26. Smetana, J.G. Parenting Styles and Conceptions of Parental Authority during Adolescence. Child Dev. 1995, 66, 299-316. [CrossRef]

27. García, F.; Gracia, E. The indulgent parenting style and developmental outcomes in South European and Latin American countries. In Parenting Across Cultures; Selin, H., Ed.; Springer: Dordrecht, The Netherlands, 2014; pp. 419-433. [CrossRef]

28. García, F.; Gracia, E. Is always Authoritative the Optimum Parenting Style? Evidence from Spanish Families. Adolescence 2009, 44, 101-131.

29. Baumrind, D. The Influence of Parenting Style on Adolescent Competence and Substance use. J. Early Adolesc. 1991, 11, 56-95. [CrossRef]

30. Martínez, I.; Cruise, E.; García, Ó.F.; Murgui, S. English Validation of the Parental Socialization Scale-ESPA29. Front. Psychol. 2017, 8, 1-10. [CrossRef]

31. Fuentes, M.C.; García, F.; Gracia, E.; Lila, M. Autoconcepto y Consumo De Sustancias En La Adolescencia. Adicciones 2011, 23, 237-248. [CrossRef]

32. Gómez-Ortiz, O.; Romera, E.M.; Ortega-Ruiz, R.; Del Rey, R. Parenting Practices as Risk or Preventive Factors for Adolescent Involvement in Cyberbullying: Contribution of Children and Parent Gender. Int. J. Environ. Res. Public Health 2018, 15, 2664. [CrossRef]

33. Martínez, I.; García, J.F.; Yubero, S. Parenting Styles and Adolescents' Self-Esteem in Brazil. Psychol. Rep. 2007, 100, 731-745. [CrossRef]

34. Fuentes, M.C.; Alarcón, A.; Gracia, E.; García, F. School Adjustment among Spanish Adolescents: Influence of Parental Socialization. Cultura y Educacion 2015, 27, 1-32. [CrossRef]

35. Moreno-Ruiz, D.; Estévez, E.; Jiménez, T.I.; Murgui, S. Parenting Style and Reactive and Proactive Adolescent Violence: Evidence from Spain. Int. J. Environ. Res. Public Health 2018, 15, 2634. [CrossRef]

36. Martínez, I.; Fuentes, M.; García, F.; Madrid, I. The Parenting Style as Protective or Risk Factor for Substance use and other Behavior Problems among Spanish Adolescents. Adicciones 2013, 25, 235-242. [CrossRef] 
37. Crespo-Ramos, S.; Romero-Abrio, A.; Martínez-Ferrer, B.; Musitu, G. Psychosocial Variables and Overt School Violence among Adolescents. Psychosoc. Interv. 2017, 26, 125-130. [CrossRef]

38. Martínez-Ferrer, B.; Romero-Abrio, A.; Moreno-Ruiz, D.; Musitu, G. Child-to-Parent Violence and Parenting Styles: Its Relations to Problematic use of Social Networking Sites, Alexithymia, and Attitude Towards Institutional Authority in Adolescence. Psychosoc. Interv. 2018, 27, 163-171. [CrossRef]

39. Cerezo, F.; Ruiz-Esteban, C.; Lacasa, C.S.; Gonzalo, J.J.A. Dimensions of Parenting Styles, Social Climate, and Bullying Victims in Primary and Secondary Education. Psicothema 2018, 30, 59-65. [CrossRef]

40. Rodrigues, Y.; Veiga, F.; Fuentes, M.C.; García, F. Parenting and Adolescents' Self-Esteem: The Portuguese Context. Revista de Psicodidáctica 2013, 18, 395-416. [CrossRef]

41. Martínez, I.; García, J.F.; Camino, L.; Camino, C. Parental Socialization: Brazilian Adaptation of the ESPA29 Scale. Psicologia 2011, 21, 640-647. [CrossRef]

42. Marchetti, B.; Caldari, L.; Palmonari, A. Concetto Di sérelazioni Familiari e Valori; Il Ponte Vecchio: Bologna, Italy, 1998.

43. Albertí-i-Amengual, A.; Gabaldón-Sisternas, S.; Frías-Navarro, M.D. Peruvian parenting styles, adolescents: Personal competence and internalization of values. In Parenting: Cultural Influences and Impact on Childhood Health and Well-Being; García, F., Ed.; Nova Science Publishers: Hauppauge, NY, USA, 2015; pp. 61-75.

44. Garcia, O.F.; Lopez-Fernandez, O.; Serra, E. Raising Spanish Children with an Antisocial Tendency: Do we Know what the Optimal Parenting Style is? J. Interpers. Violence 2018. [CrossRef]

45. Di Maggio, R.; Zappulla, C. Mothering, Fathering, and Italian Adolescents' Problem Behaviors and Life Satisfaction: Dimensional and Typological Approach. J. Child Fam. Stud. 2014, 23, 567-580. [CrossRef]

46. Calafat, A.; García, F.; Juan, M.; Becoña, E.; Fernández-Hermida, J.R. Which Parenting Style is More Protective Against Adolescent Substance use? Evidence within the European Context. Drug Alcohol Depend. 2014, 138, 185-192. [CrossRef]

47. Wolfradt, U.; Hempel, S.; Miles, J.N.V. Perceived Parenting Styles, Depersonalisation, Anxiety and Coping Behaviour in Adolescents. Pers. Individ. Differ. 2003, 34, 521-532. [CrossRef]

48. Turkel, Y.D.; Tezer, E. Parenting Styles and Learned Resourcefulness of Turkish Adolescents. Adolescence 2008, 43, 143-152.

49. Valente, J.Y.; Cogo-Moreira, H.; Sanchez, Z.M. Gradient of Association between Parenting Styles and Patterns of Drug use in Adolescence: A Latent Class Analysis. Drug Alcohol Depend. 2017, 180, 272-278. [CrossRef]

50. Villalobos, J.A.; Cruz, A.V.; Sánchez, P.R. Parental Styles and Psychosocial Development in High-School Students. Rev. Mex. Psicol. 2004, 21, 119-129.

51. López-Jáuregui, A.; Oliden, P.E. Adaptation of the ESPA29 Parental Socialization Styles Scale to the Basque Language: Evidence of Validity. Span. J. Psychol. 2009, 12, 737-745. [CrossRef]

52. Martínez, I.; García, F.; Musitu, G.; Yubero, S. Family Socialization Practices: Factor Confirmation of the Portuguese Version of a Scale for their Measurement. Revista de Psicodidactica 2012, 17, 159-178.

53. McCrae, R.R.; Zonderman, A.B.; Costa, P.T., Jr.; Bond, M.H.; Paunonen, S.V. Evaluating Replicability of Factors in the Revised NEO Personality Inventory: Confirmatory Factor Analysis Versus Procrustes Rotation. J. Pers. Soc. Psychol. 1996, 70, 552-566. [CrossRef]

54. García, F.; Fernández-Doménech, L.; Veiga, F.H.; Bono, R.; Serra, E.; Musitu, G. Parenting styles and parenting practices: Analyzing current relationships in the Spanish context. In Parenting: Cultural Influences and Impact on Childhood Health and Well-Being; García, F., Ed.; Nova Science Publishers, Inc.: Hauppauge, NY, USA, 2015; pp. 17-31.

55. Felson, R.B.; Zielinski, M.A. Childrens Self-Esteem and Parental Support. J. Marriage Fam. 1989, 51, 727-735. [CrossRef]

56. Barber, B.K.; Chadwick, B.A.; Oerter, R. Parental Behaviors and Adolescent Self-Esteem in the United-States and Germany. J. Marriage Fam. 1992, 54, 128-141. [CrossRef]

57. Garcia, F.; Martínez, I.; Balluerka, N.; Cruise, E.; Garcia, O.F.; Serra, E. Validation of the Five-Factor Self-Concept Questionnaire AF5 in Brazil: Testing Factor Structure and Measurement Invariance Across Language (Brazilian and Spanish), Gender, and Age. Front. Psychol. 2018, 9, 2250. [CrossRef] [PubMed]

58. Tomás, J.M.; Oliver, A. Confirmatory Factor Analysis of a Spanish Multidimensional Scale of Self-Concept. Revista Interamericana de Psicología 2004, 38, 285-293.

59. García, J.F.; Musitu, G.; Riquelme, E.; Riquelme, P. A Confirmatory Factor Analysis of the "Autoconcepto Forma 5" Questionnaire in Young Adults from Spain and Chile. Span. J. Psychol 2011, 14, 648-658. [CrossRef] 
60. Garcia, F.; Gracia, E.; Zeleznova, A. Validation of the English Version of the Five-Factor Self-Concept Questionnaire. Psicothema 2013, 25, 549-555. [CrossRef]

61. García, F.; Musitu, G. AF5: Self-Concept Form 5, 3rd ed.; TEA Editions: Madrid, Spain, 2009; p. 39.

62. García, F.; Musitu, G. AF5: Self-Concept Form 5; TEA Editions: Madrid, Spain, 1999; p. 39.

63. Murgui, S.; García, C.; García, A.; García, F. Self-Concept in Young Dancers and Non-Practitioners: Confirmatory Factor Analysis of the AF5 Scale. Rev. Psicol. Deporte 2012, 21, 263-269.

64. Elosua, P.; Muñiz, J. Exploring the Factorial Structure of the Self-Concept: A Sequential Approach using CFA, MIMIC, and MACS Models, Across Gender and Two Languages. Eur. Psychol. 2010, 15, 58-67. [CrossRef]

65. Cerrato, S.M.; Sallent, S.B.; Aznar, F.C.; Pérez, E.G.; Carrasco, M.G. Psychometric Analysis of the AF5 Multidimensional Scale of Self-Concept in a Sample of Adolescents and Adults in Catalonia. Psicothema 2011, 23, 871-878.

66. Mendo-Lazaro, S.; Polo-Del-Rio, M.I.; Amado-Alonso, D.; Iglesias-Gallego, D.; Leon-Del-Barco, B. Self-Concept in Childhood: The Role of Body Image and Sport Practice. Front. Psychol. 2017, 8, 853. [CrossRef]

67. Martínez-Martínez, F.D.; González-Hernández, J. Self-Concept, Physical Exercise and its Response in Teenagers. Relationship with Academic Achievement. Revista Iberoamericana de Educación 2017, 73, 87-108.

68. Ortega, F.Z.; Santos, E.O.Z.; Moral, P.V.; Fernández, S.R.; Sánchez, M.C.; Molina, J.J.M. Analysis of Resilience, Self-Concept and Motivation in Judo as Gender. Revista de Psicología del Deporte 2017, 26, 71-82.

69. Riquelme, M.; Garcia, O.F.; Serra, E. Psychosocial Maladjustment in Adolescence: Parental Socialization, Self-Esteem, and Substance use. An. Psicol. 2018, 34, 536-544. [CrossRef]

70. Saiz, J.; Alvaro, J.L.; Martinez, I. Relation between Personality Traits and Personal Values in Cocaine-Dependent Patients. Adicciones 2011, 23, 125-132. [CrossRef] [PubMed]

71. Galdós, J.S.; Sánchez, I.M. Relationship between Cocaine Dependence Treatment and Personal Values of Openness to Change and Conservation. Adicciones 2010, 22, 51-58.

72. González-Carrasco, M.; Casas, F.; Viñas, F.; Malo, S.; Gras, M.E.; Bedin, L. What Leads Subjective Well-being to Change throughout Adolescence? An Exploration of Potential Factors. Child Indic. Res. 2017, 10, 33-56. [CrossRef]

73. Rohner, R.P.; Saavedra, J.; Granum, E.O. Development and Validation of the Parental Acceptance Rejection Questionnaire: Test Manual. Cat. Select. Doc. Psychol. 1978, 8, 17-48.

74. Stattin, H.; Kerr, M. Parental Monitoring: A Reinterpretation. Child Dev. 2000, 71, 1072-1085. [CrossRef]

75. Byrne, B.M.; Shavelson, R.J. On the Structure of Social Self-Concept for Pre-, Early, and Late Adolescents: A Test of the Shavelson, Hubner, and Stanton (1976) Model. J. Pers. Soc. Psychol. 1996, 70, 599-613. [CrossRef]

76. Yin, P.; Fan, X.T. Assessing the Factor Structure Invariance of Self-Concept Measurement Across Ethnic and Gender Groups: Findings from a National Sample. Educ. Psychol. Meas. 2003, 63, 296-318. [CrossRef]

77. Pérez, J.F.G.; Navarro, M.D.F.; Llobell, J.P. Randomness Tests Versus F-Distribution when the Measurement Scale is Discrete. Psicothema 2000, 12, 253-256.

78. Satorra, A.; Bentler, P.M. A Scaled Difference Chi-Square Test Statistic for Moment Structure Analysis. Psychometrika 2001, 66, 507-514. [CrossRef]

79. Hu, L.; Bentler, P.M. Cutoff Criteria for Fit Indexes in Covariance Structure Analysis: Conventional Criteria Versus New Alternatives. Struct. Equ. Model. 1999, 6, 1-55. [CrossRef]

80. Bentler, P.M.; Bonett, D.G. Significance Tests and Goodness of Fit in the Analysis of Covariance Structures. Psychol. Bull. 1980, 88, 588-606. [CrossRef]

81. Cheung, G.W.; Rensvold, R.B. Evaluating Goodness-of-Fit Indexes for Testing Measurement Invariance. Struct. Equ. Model. 2002, 9, 233-255. [CrossRef]

82. Akaike, H. Factor Analysis and AIC. Psychometrika 1987, 52, 317-332. [CrossRef]

83. Kenny, D.A.; Kaniskan, B.; McCoach, D.B. The Performance of RMSEA in Models with Small Degrees of Freedom. Sociol. Methods. Res. 2015, 44, 486-507. [CrossRef]

84. Musitu, G.; García, J.F. Consequences of the Family Socialization in the Spanish Culture. Psicothema 2004, 16, 288-293.

85. Ahn, J.A.; Lee, S. Peer Attachment, Perceived Parenting Style, Self-Concept, and School Adjustments in Adolescents with Chronic Illness. Asian Nurs. Res. 2016, 10, 300-304. [CrossRef]

86. Álvarez-García, D.; García, T.; Barreiro-Collazo, A.; Dobarro, A.; Antúnez, A. Parenting Style Dimensions as Predictors of Adolescent Antisocial Behavior. Front. Psychol. 2016, 7, 1383. [CrossRef] 
87. Holdsworth, C.; Laverty, L.; Robinson, J. “Drinking Definitely Wasn't Something that we'd seen Anybody do": The Relevance of Childhood Experiences of Family Drinking for Parenting Strategies of Alcohol Socialisation. Fam. Relatsh. Soc. 2017, 6, 37-52. [CrossRef]

88. McLaughlin, A.; Campbell, A.; McColgan, M. Adolescent Substance use in the Context of the Family: A Qualitative Study of Young people's Views on Parent-Child Attachments, Parenting Style and Parental Substance use. Subst. Use Misuse 2016, 51, 1846-1855. [CrossRef] [PubMed]

89. Barry, C.T.; Frick, P.J.; Grafeman, S.J. Child Versus Parent Reports of Parenting Practices: Implications for the Conceptualization of Child Behavioral and Emotional Problems. Assessment 2008, 15, 294-303. [CrossRef] [PubMed]

(C) 2019 by the authors. Licensee MDPI, Basel, Switzerland. This article is an open access article distributed under the terms and conditions of the Creative Commons Attribution (CC BY) license (http:/ / creativecommons.org/licenses/by/4.0/). 